\title{
Acquisition and retention of viruses by Trichomonas vaginalis
}

\author{
F F PINDAK, M MORA DE PINDAK, B M HYDE, W A GARDNER JR \\ From the University of South Alabama College of Medicine, Mobile, Alabama, USA
}

SUMMARY Recently described occurrence of virus-like particles (VLP) in some strains of Trichomonas vaginalis suggests the possibility that the pathogenic significance of this organism may be broadened by its potential for viral transmission. Inasmuch as neither the source nor the host range of the VLP are known, any hazard which they may present for man cannot be estimated. A model has been established for the study of acquisition of known human viruses by $T$ vaginalis. Tissue cultures were infected with two reoviruses and a fresh isolate of genital herpes simplex virus (HSV). A squirrel monkey reovirus was also included in the study. $T$ vaginalis was inoculated into the virus cultures three days later. The progress of virus acquisition by the trichomonads was monitored by transmission electron microscopy and by culture. Virus-containing cell fragments were engulfed by trichomonads and internalised in vacuoles. After digestion of cellular debris only virus particle aggregates were retained. Viable reoviruses were recovered from the trichomonads for nine days, and HSV for six days. The results suggest the possibility of transmission of at least some viruses by $T$ vaginalis.

Trichomoniasis is one of the most common sexually transmitted diseases. Its causative organism, Trichomonas vaginalis, has been largely ignored by the scientific community, in part because the infection it causes, although usually chronic, is not life threatening and only rarely debilitating. Information regarding the specific events of host reaction to this parasite is scant, and even less is known about its long-term effects and its relationship to other microorganisms. That $T$ vaginalis may serve as a "vector" for other microoroganisms is a theoretical possibility in view of its ability to ingest Neisseria gonorrhoeae,' other bacteria, ${ }^{2}$ and mycoplasma. ${ }^{3}$ Unidentified virus particles in certain strains of the organism were also recently described.$^{45}$

In axenic culture $T$ vaginalis is usually described as a pear-shaped free-swimming protozoon. In cocultures with mammalian cells, however, it has the tendency to attach to these cells or to the underlying surface, and to exhibit amoeboid movement, ${ }^{6}$ with evidence of phagocytosis both in vitro and in vivo. ${ }^{27}$

Tissue culture monolayers inoculated with $T$ vagin-

Address for reprints: Frank F Pindak, Department of Pathology, University of South Alabama, College of Medicine, 2451 Fillingim Street, Mobile, Alabama 36617.

Accepted for publication 18 August 1989 alis become disrupted, partly owing to the action of the cell detaching factor (TvCDF) which it releases into the medium. ${ }^{8}$ Upon prolonged incubation the tissue culture cell count is markedly reduced. This cell deficit could be influenced by the phagocytic activity of the parasite.

We present data which show that $T$ vaginalis cocultivated with tissue cultures infected with known viruses ingest large portions of virus-containing cells. Infectious virus particles are retained by the organism for several days. Our results imply that, under certain circumstances, $T$ vaginalis can play the role of a carrier of infectious agents with their own pathological consequences.

\section{Materials and methods}

MICROORGANISMS AND TISSUE CULTURES

Reoviruses were obtained from the American Type Culture Collection (type 1, ATCC VR-230; type 2, ATCC VR-231). Reovirus-like squirrel monkey agent (SMR 1239) was recovered from an enlarged lymph node of a dead squirrel monkey, and herpes simplex virus (HSV) from cervical swab of a local patient; primary isolation of both agents was done in our laboratory. $T$ vaginalis strain Baltimore 42 was obtained through the courtesy of Dr B M Honigberg.

The reoviruses were propagated in HamLu cells, a 
continuous line derived in our laboratory from baby hamster lung tissue. HSV was isolated and further maintained in human rhabdomyosarcoma (RD) cells obtained from the American Type Culture Collection (ATCC CCL136). Trypsinised tissue cultures were suspended in medium 199 with $10 \%$ fetal bovine serum (FBS) and grown to full monolayer in $75 \mathrm{~cm}^{2}$ flasks. The medium was removed and viruses were inoculated at 1:1 multiplicity ratio. After a $3 \mathrm{~h}$ period of adsorption the infected monolayers were rinsed, and $20 \mathrm{ml}$ of medium 199 with $2 \%$ FBS were added to each flask. Following additional 3-day incubation at $37^{\circ} \mathrm{C}$ the medium was replaced with $20 \mathrm{ml}$ of GMP medium ${ }^{8}$ containing approximately $10^{6} T$ vaginalis previously grown in trypticase-yeast extract-maltose (TYM) medium. ${ }^{9}$

\section{ELECTRON MICROSCCOPY}

After further incubation at $37^{\circ} \mathrm{C}$ for 2 days representative cultures were fixed and processed for transmission electron microscopy (TEM). Double-concentrated fixative was added at 1:1 ratio to each culture, resulting in final concentration of $2 \%$ glutaraldehyde and $0.5 \%$ paraformaldehyde, buffered to $\mathrm{pH} 7.2$ with $0.1 \mathrm{M}$ sodium cacodylate. Control cultures treated in the same manner were: (a) tissue culture only; (b) virus-infected cultures; (c) tissue culture inoculated with trichomonads only. After overnight storage at $4^{\circ} \mathrm{C}$ adherent cells (mostly trichomonads) were scraped off and sedimented by low speed centrifugation $(800 \mathrm{~g} / 10 \mathrm{~min})$. The resulting soft pellet was postfixed in $1 \%$ osmium tetroxide in $0.1 \mathrm{M}$ sodium cacodylate buffer $\mathrm{p} ! \mathbf{7} 7 \cdot 2$. The samples were dehydrated in a series of graded ethanol and embedded in Spurr's Low Viscosity Resin. Ultrathin sections were cut with LKB Ultrotome III, stained with uranyl acetate and lead nitrate, and examined in a Phillips 301 TEM.

\section{VIRUS ASSAY}

At the time of inoculation with $T$ vaginalis and at periodic intervals thereafter, the presence of reoviruses was demonstrated by positive agglutination tests with human erythrocytes type 0 by the method recommended for identification of viral isolates, ${ }^{10}$ and by culture in HamLu cells when necessary. HSV was monitored by the production of characteristic CPE in RD cells.

\section{Results}

\section{UPTAKE OF REOVIRUSES}

TEM examination of reovirus-infected HamLu tissue cultures (control) at the time of superinfection with $T$ vaginalis showed typical intracytoplasmic aggregates of mature virus particles in most cells (fig 1a). Normal $T$ vaginalis organisms frequently contained vacuoles, but a thorough search failed to reveal any structures resembling virus particles (fig $1 \mathrm{~b}$ ). Examinations of matched virus-infected tissue cultures which were incubated for 2 additional days with $T$ vaginalis revealed the following stages of virus acquisition by the trichomonads: (1) virus-containing HamLu cells were intimately surrounded by the trichomonads, with initial steps of phagocytic invagination of the cell periphery (fig 2a); (2) distinctly recognisable fragments of infected cells, with virus aggregates intact, were seen in the vacuoles of trichomonads (fig 2b); (3) the food vacuole decreased in size when the cell remnants were digested, leaving well defined arrays of virus particles (fig 2c); (4) the space previously occupied by the vacuoles was reclaimed by the cytoplasm of the trichomonads, leaving only apparently still intact virus particles (fig 2d). It is postulated that at this stage the uptake of virus by the trichomonads was completed. The features here described were found with both types of human reovirus, as well as with the squirrel monkey isolate.

Cocultures of $T$ vaginalis with reovirus type 2 were used for study of the fate of incorporated virus. Portions of frozen-thawed cultures were centrifuged and the supernatants were assayed on 12 successive days for the presence of viral haemagglutinin. In unadjusted cultures the haemagglutinin was demonstrated up to 4 days of incubation with trichomonads. Cultures in which the $\mathrm{pH}$ was adjusted daily to near neutrality remained positive for additional 2 days. These intervals coincided with the presence of viable (motile) trichomonads. When TYM medium (adjusted to $\mathrm{pH} \mathrm{7.0)}$ was added to the culture to facilitate further propagation of trichomonads, the haemagglutinin was present up to the 9th day, showing gradual decline in titre from 1:16 on the 2 nd day to less than 1:2 on the 9th day. However, reinoculation of the frozen-thawed trichomonads at that time into normal HamLu cells still indicated the presence of active virus. This was shown by the appearance of CPE and by positive haemagglutinin tests obtained with the tissue culture supernatant 5 days after inoculation.

\section{UPTAKE OF HSV}

Three-day-old cultures of HSV in RD cells were inoculated with $T$ vaginalis in the same manner as were HamLu cells infected with reoviruses (see above). The presence of virus particles in RD cells was verified by TEM of a matched virus control culture. The assembly site of HSV is in the nucleus from which extra-cellular release in single units or small aggregates is channeled through cytoplasm. Virus clusters of similar size were found in trichomonads cocultivated for 2 days with infected cells (fig 3). Frozen-thawed trichomonads collected on the 2nd and 3rd day released active HSV, as evidenced by the development of characteristic CPE 


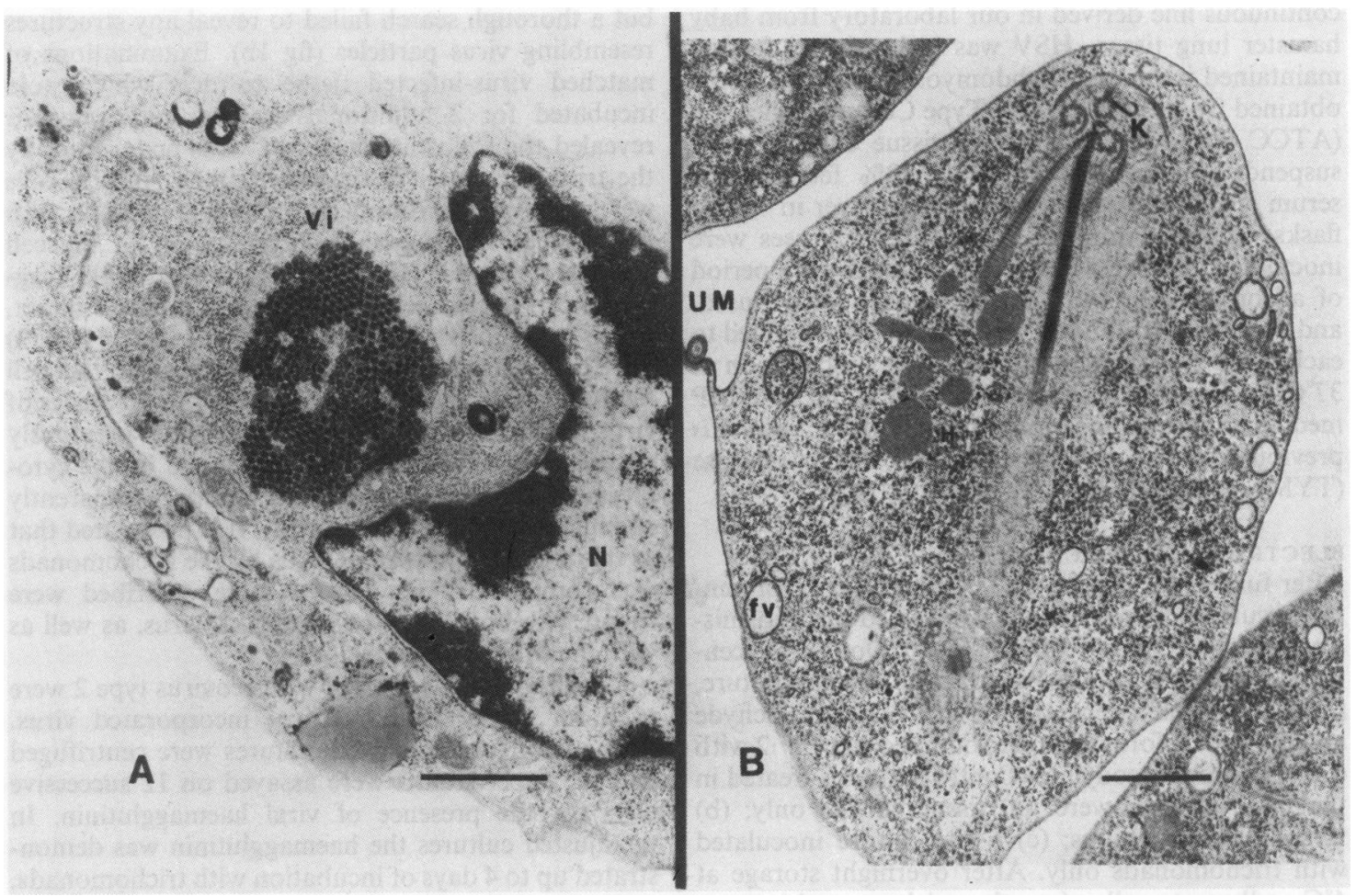

Fig 1 Verification of viral infection of tissue culture and of absence of virus particles in normal $T$ vaginalis at the time of coculture initiation. (a) HamLu cell infected with reovirus; $N=$ nucleus; $V i=$ intracytoplasmic viral inclusion consisting of a large array of mature virus. (b) Normal $T$ vaginalis; Um-undulating membrane; $K=$ Kinetosome; Fv $=$ food vacuole. TEM. Bar $=1 \mu \mathrm{m}$.

in RD cells inoculated with thus lysed trichomonads. Failure to recover the virus at later intervals was attributed to a drop of $\mathrm{pH}$ of the cultures to the level at which HSV is inactivated. In GMP medium, the $\mathrm{pH}$ of late stationary cultures of $T$ vaginalis ( 3 to 4 days old) normally decreases to the $4 \cdot 2$ to $4 \cdot 1$ value, and there is a steady loss of motility; at $37^{\circ} \mathrm{Ca} 3 \mathrm{~h}$ exposure of $\mathrm{HSV}$ in buffer $\mathrm{pH} 4$ and 5 resulted in complete and 2-log loss of titre, respectively (data not shown). Therefore, acidinactivation of HSV was indeed likely in cultures held beyond 3 days. When in a supplementary experiment, designed to parallel the protocol above, the culture was adjusted twice daily to near neutral $\mathrm{pH}$ by addition of $0.1 \mathrm{M} \mathrm{NaOH}$ the life of the organisms was extended and the virus recovery in RD cells (showing characteristic CPE) was successful for 6 consecutive days after introduction of $T$ vaginalis into the virus culture.

\section{Discussion}

In recent years a number of protozoan species have been reported to contain virus-like particles (VLP).
These include Entamoeba histolytica, ${ }^{11-13}$ Giardia lamblia, ${ }^{14}$ Leishmania hertigi ${ }^{15}$ L brazilensis, ${ }^{16}$ and $T$ vaginalis. $^{45}$ In each instance the VLP were detected by electron microscopy. Culture procedures requiring isolation and definitive characterisation of viruses were unsuccessful or not attempted. Thus, it is not known whether the described VLP were "natural" inhabitants of the particular protozoan species or were acquired from the host in which the protozoa resided. Should the latter be the case, then protozoan infection or infestation could be a novel means of viral transmission and lead to medical consequence wholly apart from those caused by the parasites themselves. This theoretical possibility has been suggested earlier. A close association between $T$ vaginalis infection and presence of vaginal papillomas was reported more than a decade ago. ${ }^{17}$ In a recent clinical study attention was focused on a higher than random incidence of cervical neoplasia in patients with proven human papilloma virus and chlamydial cervical infections. ${ }^{18}$ The possibility that $T$ vaginalis can serve as a vector of other infections of the upper genital tract was suggested by the evidence of firm attachment of bacteria to its 


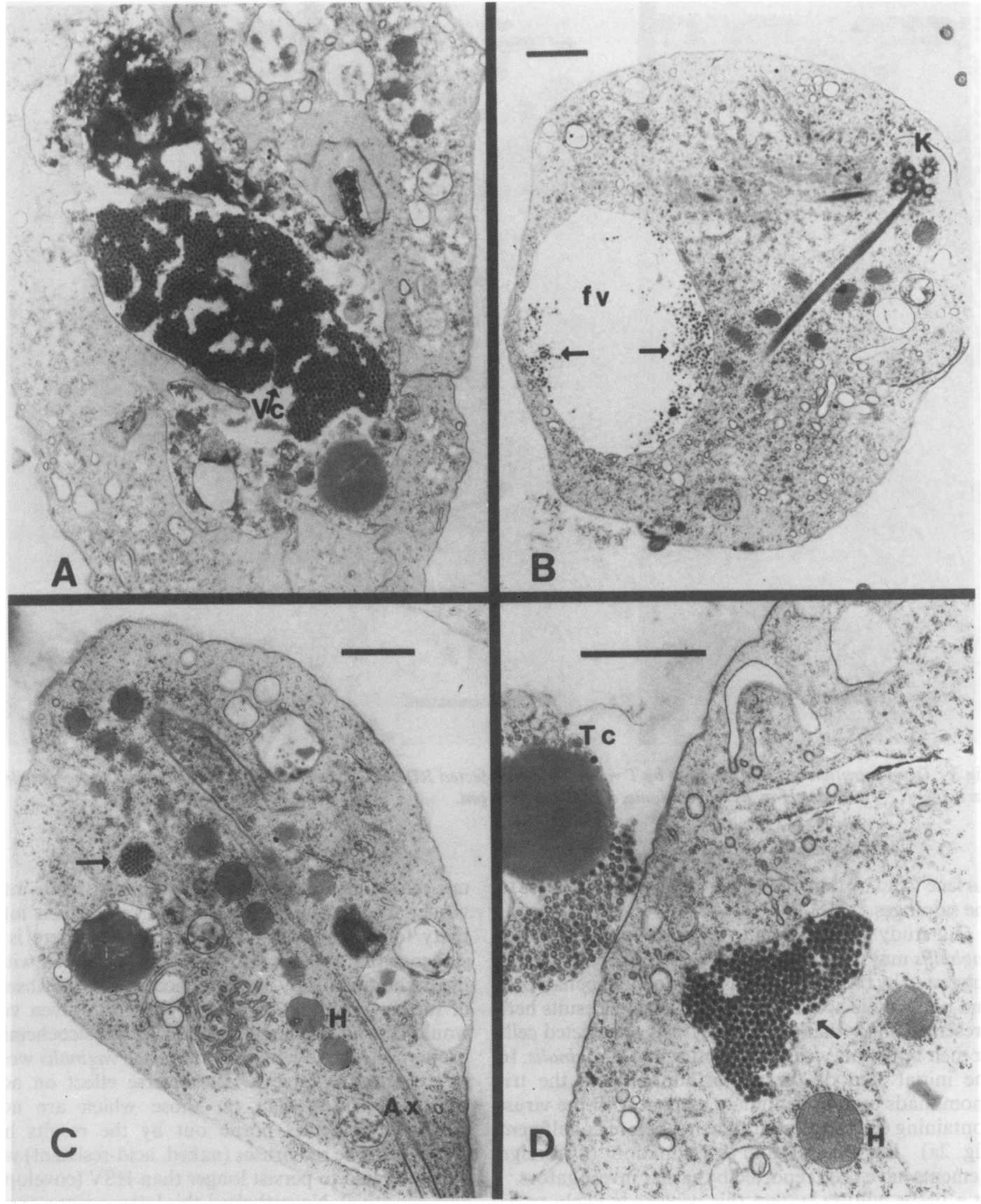

Fig 2 Stages of reovirus acquisition by $T$ vaginalis (a) Engulfment of cell remnant containing a virus crystal (Vc) by trichomonads; magnification as in $C$; (b) Infected cell debris entrapped in a large vacuole $(F v)$ of $T$ vaginalis; arrows indicate remnants of virus aggregate. $K=$ Kinetoplast. $(c)$ contracted vacuole, with cell debris digested, showing only a portion of viral crystal (arrow). (d) arrow shows partial resolution of vacuole boundary and incorporation of virus particles into the cytoplasm of the organism; TC = remnant of virus-infected HamLu cell. TEM. Bar $=1 \mu \mathrm{m}$. 


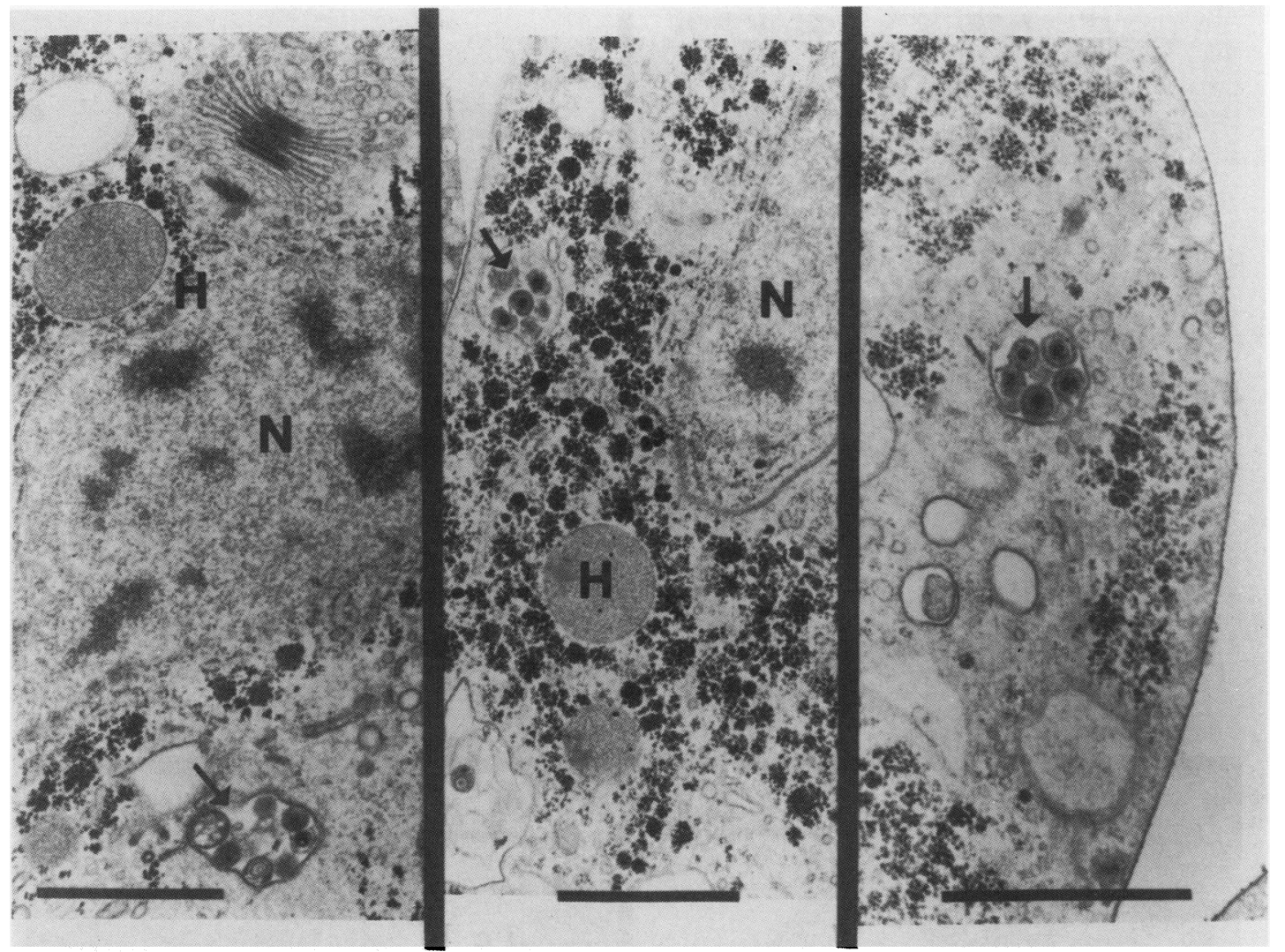

Fig 3 Demonstration of HSV acquired by $T$ vaginalis from infected RD cells. Arrows indicate intravacuolar pockets of viral particles; $N=$ nucleus; $H=$ hydrogenosome. TEM. Bar $=1 \mu \mathrm{m}$.

surface ${ }^{19}$ and by the organism's ability to gain access to the salpinges. ${ }^{20}$

Our study was designed to test the hypothesis that $T$ vaginalis may acquire human viruses. This theory was suggested by the observations of amoeboid behaviour ${ }^{6}$ and phagocytic activity of the parasite. ${ }^{27}$ Results here presented show that by phagocytosis of infected cells or their remnants viruses gain entry into $T$ vaginalis. In the initial step of the acquisition process the trichomonads establish intimate contact with the viruscontaining cells and cell fragments before engulfment (fig 2a). Engulfment and invagination of foreign elements have been reported by earlier investigators. ${ }^{27}$ In a tissue culture system this process is likely to be facilitated by the activity of the TVCDF which detaches cells from their anchorage on the supporting surface, ${ }^{8}$ and thus makes them more readily available for engulfment and phagocytosis. Remarkably large portions of virus-infected cells can be entrapped in the vacuoles of the trichomonads (fig $2 \mathrm{~b}$ ). The cytoplas- mic remnants are digested fairly rapidly, while intact virus particles remain (fig $2 \mathrm{~d}$ ) and retain their infectivity for a number of days. At present there is no evidence that human viruses can be sustained within the trichomonads by active replication. In the absence of further proliferation the survival of a given virus would depend to a large extent on its physicochemical properties. The low $\mathrm{pH}$ inherent to $T$ vaginalis would be expected to have a less adverse effect on acidresistant viruses than on those which are acidsensitive. This was borne out by the results here presented. The reoviruses (naked, acid-resistant) were demonstrated to persist longer than HSV (enveloped, acid-sensitive). Nevertheless, this latter agent was also found to survive for at least 6 days. Thus, by sexual contact with a double-infected individual, even such vulnerable virus, in theory could be transmitted via the $T$ vaginalis. Inasmuch as the current laboratory procedures for detection of $T$ vaginalis and HSV or any virus are mutually exclusive, that is, methods for 
detection of one are unsuited for the other, it may be advisable to test $T$ vaginalis-positive patients for viral infections as well.

We thank the South Alabama Medical Science Foundation for support of this study. The results were presented in part of the 88th Annual Meeting of the American Society for Microbiology, Miami Beach, Florida, 8-13 May 1988.

\section{References}

1 Francioli P, Shio H, Roberts RB, Muller M. Phagocytosis and killing of Neisseria gonorrhoeae by Trichomonas vaginalis. $J$ Infect Dis 1983;147:87-94.

2 Nielsen HM. Phagocytosis by Trichomonas vaginalis Donne. Structural and electron-histochemical observations. Proc 7th Internat Congress of Electron Microscopy, Grenoble 1970: 389-90.

3 Scholtyseck E, Teras J, Kasakova I, Sethi KK. Electron microscopic observations on the interaction of Mycoplasma fermentans with Trichomonas vaginalis. Z Parasitenkd 1985;71:435-42.

4 Wang A, Wang CC, Alderete JF. Trichomonas vaginalis phenotypic variation occurs only among trichomonads infected with double stranded RNA virus. J Exp Med 1987;166:142-50.

5 Wang AL, Wang CC. The double-stranded RNA in Trichomonas vaginalis may originate from virus-like particles. Proc Natl Acad Sci USA 1986;83:7956-60.

6 Heath JP. Behaviour and pathogenicity of Trichomonas vaginalis in epithelial cell cultures. A study by light and scanning electron microscopy. Br J Venereal Dis 1981;57:106-17.

7 Ovcinnikov NM, Deletorskij VV, Turanova EN, Yashkova GN. Further studies of Trichomonas vaginalis with transmission and scanning electron microscopy. Br J Venereal Dis 1975;51: 357-75.
8 Pindak FF, Gardner WA Jr, Mora de Pindak M. Growth and cytopathogenicity of Trichomonas vaginalis in tissue cultures. J Clin Microbiol 1986;23:672-8.

9 Diamond LS. The establishment of various trichomonads of animals and man in axenic cultures. $J$ Parasitol 1957;43:488-90.

10 Rosen L. Reoviruses. In: Lennette EH, Schmidt NJ, eds. Diagnostic procedures for viral, rickettsial and chlamydial infections. Washington DC: Am Pub Health Assoc Inc, 1979:577-84.

11 Bird RG, McCaul TF, Knight R. Rhabdo-virus-like particles of Entamoeba histolytica. Trans R Soc Trop Med Hyg 1974;68:2.

12 Knight R, Bird RG, McCaul TF. Fine structural changes at Entamoeba histolytica rabbit kidney cell (RK13) interface. Ann Trop Med Parasitol 1975;69:197-202.

13 Mattern CFT, Diamond LS, Daniel WA. Viruses of Entamoeba histolytica. II. Morphogenesis of the polyhedral particle $\left(\mathrm{ABRM}_{2} \rightarrow\right.$ HK-9) $\rightarrow$ HB-301 and the filamentous agent $(\mathrm{ABRM})_{2} \rightarrow$ HK-9. J Virol 1972;9:342-58.

14 Feely DE, Chase DG, Hardin EL, Erlandsen SL. Ultrastructural evidence for the presence of bacteria, viral-like particles, and mycoplasma-like organisms associated with Giardia spp. $J$ Protozool 1988;35:151-8.

15 Eley SM, Molyneux DH, Moore NF. Investigation of virus-like particles in Leishmania hertigi. Microbios 1987;51:145-9.

16 Tarr PI, Aline RF Jr, Smiley BL, Scholler J, Keithly J, Stuart K. LRI: a candidate RNA virus of Leishmania. Proc Natl Acad Sci USA 1988;85:9572-5.

17 Rodgerson EB. Vulvovaginal papillomas and Trichomonas vaginalis. Obstet Gynecol 1972;40:327-33.

18 Allerding TJ, Jordan.SW, Boardman RE. Association of human papillomavirus and chlamydia infections with incidence cervical neoplasia. Acta Cytol 1985;29:653-60.

19 Keith LG, Friberg J, Fullan N, Bailey R, Berger GS. The possible role of Trichomonas vaginalis as a "vector" for the spread of other pathogens. Int J Fertil 1986;31:272-7.

20 Mardh PA, Westrom L. Tubal and cervical cultures in acute salpingitis with special reference to Mycoplasma hominis and T strain Mycoplasmas. Br J Venereal Dis 1970;46:179-86. 